\title{
Influence of chronic comorbidity and medication on the efficacy of treatment in patients with diabetes in general practice
}

\begin{abstract}
Background

Evidence on the influence of comorbidity and comedication on clinical outcomes in patients with type 2 diabetes mellitus is scarce.

Aim

To ascertain the effect of five chronic diseases ljoint disorder, respiratory disease, anaemia, malignancy, depression) and three chronically used drugs (non-steroid antiinflammatory drugs [NSAIDs], corticosteroids, antidepressants) on treatment for

hypoglycaemia in patients with type 2 diabetes.

\section{Design and setting}

Retrospective cohort study in a variety of practices across Flanders, Belgium.

\section{Method}

A retrospective cohort study was conducted, based on data from Intego, a general practicebased continuous morbidity registry. Multiple logistic regression analysis was used to predict the change in glycosylated haemoglobin (HbA1c) levels related to comorbidity, comedication, and a combination of both in 3416 patients with type 2 diabetes. Adjustments were made for age, sex, and diabetestreatment group (diet, oral antidiabetic drugs, combination treatment, insulin).

\section{Results}

Concomitant joint and respiratory disorders, as well as the chronic use of NSAIDs and corticosteroids, either separately or in combination, were significantly associated with the worsening of $\mathrm{HbA1c}$ levels. Anaemia, depression, malignancy, and antidepressants had no statistically significant influence on the efficacy of treatment for hypoglycaemia.

Type 2 diabetes mellitus is a frequent chronic disorder.1,2 The recommended strategy for achieving glucose control is to establish a metabolic target and to adjust treatment to achieve this. A generally accepted target for glucose control is a glycosylated haemoglobin ( $\mathrm{HbA} 1 \mathrm{c})$ level of $<7 \% .^{3-5}$ However, as shown in many observational studies in primary care, only about half of those patients who have type 2 diabetes achieve this..$^{6-9}$ There are several reasons for this quality gap.

One possible factor is the presence of non-diabetes-associated comorbidity; indeed, half of patients with chronic diseases have more than one. ${ }^{10}$ However, most actual guidelines focus on the management of single diseases ${ }^{11}$ and are of limited use regarding patients with multimorbidity or limited life expectancy. ${ }^{12}$ An optimal approach to treat combined disorders is not the same as the sum of optimal treatments for the separate disorders; this is a central thesis of complexity theory, which can offer a framework for managing the treatment of people with multimorbidity. ${ }^{13}$ The recent position statement of the American Diabetes Association and the European Association for the Study of Diabetes makes a first attempt to implement this approach and emphasises the need for individualised targets that take several variables, such as comorbidity, into account. ${ }^{14}$ However,
\end{abstract}

\section{Conclusion}

The presence of some comorbid diseases or drug use can impede the efficacy of treatment for type 2 diabetes. This finding supports the need to develop treatment recommendations, taking into account the presence of both chronic comorbidity and comedication. Further research must be undertaken to ascertain the effect other combinations of chronic diseases have on the efficacy of treatment of this and other diseases.

\section{Keywords}

co-medication; comorbidity; HbA1c; logistic regression; type 2 diabetes.

\section{INTRODUCTION}

WM Wami, MSc, statistician, Parasite imunoloepdemiology group, University of Edinburgh, UK. M Aerts, MD, PhD, professor of statistics, Interuniversity Institute for Statistics and Statistical Bioinformatics, Hasselt University, Diepenbeek, Belgium. F Buntinx, MD, PhD, professor of general practice:

S Bartholomeeusen, MD, PhD, GP; G Goderis, MD, PhD, GP, Department of General Practice, KU Leuven, Leuven, Belgium. C Mathieu, MD, PhD, professor of endocrinology, Department of Endocrinology, University Hospitals, Leuven, Belgium. the statement remains vague and does not present any evidence relating to its principal position change. Indeed, adaption of the clinical guidelines should be based on evidence about the complex interactions in multimorbid conditions and the reciprocal influences on disease evolution and treatment effects. ${ }^{15}$

Knowledge about the influence of specific comorbidity and comedication on treatment effects is scarce. ${ }^{16-21}$ The present study seeks to contribute to the understanding of the combined effect of comorbidity and comedication on the efficacy of glucose-lowering treatment in patients with type 2 diabetes. As such, the effect that one or more of five comorbid chronic diseases ljoint disorder, respiratory disease, anaemia, malignancy, depression) and three chronically used drugs (nonsteroid anti-inflammatory drugs [NSAIDs], corticosteroids, antidepressants) have on the efficacy of treatment in patients with type 2 diabetes mellitus was examined.

\section{METHOD}

\section{Design and data collection}

A retrospective cohort study was performed. This compared patients who had type 2 diabetes only with:

- those who also had one or more predefined comorbid diseases;

- those who were also being treated with

\section{Address for correspondence}

Frank Buntinx, Department of General Practice, Kapucijnenvoer 33, blok J, bus 7001, B 3000 Leuven, Belgium.

E-mail: frank.buntinxamed.kuleuven.be Submitted: 27 September 2012; Editor's response: 29 October 2012; final acceptance: 12 November 2012

This is the full-length article (published online 25 Mar 2013) of an abridged version published in print. Cite this article as: $\mathbf{B r} \mathbf{J}$ Gen Pract 2013; DOI: 10.3399/bjgp13X665233 


\section{How this fits in}

Most actual guidelines focus on the management of single diseases and are of limited use regarding patients with multimorbidity. Evidence supporting the update of diabetes treatment guidelines towards better application in patients with other chronic diseases or drug treatment is scarce. The results of this study show that presence of some comorbid diseases or drug use can impede the efficacy of treatment for type 2 diabetes.

one or more predefined medications; or

- those who also had one or more predefined comorbid diseases and were being treated with one or more predefined medications.

Data were collected between 1994 and 2008 from the Intego database, a general practice-based morbidity registration network from the Department of General Practice at the Katholieke Universiteit Leuven. In total, $90 \mathrm{GPs}$, who all use the medical software program Medidoc, collaborate in the Intego lintegrated computerised network) project. These GPs work in 55 practices evenly spread across Flanders, Belgium. GPs presented themselves for inclusion in the registry; before acceptance of their data, registration performance was audited using a number of algorithms that compared their results with those of all other applicants. Only the data of the practices with an optimal registration performance were included in the database. The Intego GPs prospectively and routinely registered all new diagnoses, together with new drug prescriptions, laboratory test results, and some background information (including sex and year of birth), using keywords that are internally linked to codes. ${ }^{22}$

Using specially-framed extraction software, new data were collected from the GPs' personal computers annually and entered into a central database. Registered data were continuously updated and historically accumulated for each patient. New diagnoses were classified according to a very detailed thesaurus, automatically linked to the second edition of the International Classification of Primary Care (ICPC-2) and 10th edition of the International Classification of Diseases (ICD-10). Drugs were classified according to the World Health Organization's Anatomical Therapeutic Chemical classification system.
To be included in this study, a patient's file had to include the diagnosis of type 2 diabetes. Patients aged $<30$ years at diagnosis and patients with gestational diabetes were excluded from the study.

In this study, the dependent variable was the $\mathrm{HbA1c}$ level. Covariables were:

- age;

- body mass index (BMI);

- socioeconomic status;

- sex; and

- treatment group (diet, oral antidiabetic drugs only, combined oral antidiabetic drugs and insulin, insulin only).

The presence versus absence of comorbidity and comedication were independent variables. Time of inclusion in the study was determined from the date of first and last contact.

\section{Definition of comorbidity and comedication}

In the context of this study, comorbidity was defined as the presence, along with type 2 diabetes, of at least one of the following five chronic medical conditions:

- joint disorders;

- respiratory disorders;

- anaemia;

- malignancies; and

- depression.

Comorbidity was restricted to these five chronic conditions because they were frequent and likely to be influential on the lives of patients with diabetes, but not a complication of diabetes. All malignancies were taken into account, except for nonmelanoma skin cancer.

Comedication was defined as use of at least one of three chronic drug categories associated with the defined comorbid conditions:

- NSAIDs;

- corticosteroids; and

- antidepressants.

Diabetes-related complications such as cardiovascular and microvascular diseases were not included as comorbid conditions.

\section{Main outcome measure}

The primary outcome measure was the dichotomised change in $\mathrm{HbA1c}$ level from 
the first to the last available level, ignoring all intermediate measures. An increase of the level at the end of the study was defined as 'worse HbA1c outcome' as the target for diabetes management is to lower $\mathrm{HbAlc}$ levels. This resulted in a value of 1 for the dependent variable; all other differences (improvement or stabilisation) resulted in a value of 0 .

\section{Statistical analyses}

SAS (version 9.2) and $R$ (version 2.10.0) were used to conduct stepwise logistic regression analysis. A $P$-value of $<0.05$ was considered statistically significant. In all analyses, male was used as the reference for sex, diet for treatment, and absent (0) for comorbidity and comedication. Age refers to the centred age of the patient. At each of the stages an interaction between age and sex, and between comorbidity/ comedication and different treatment groups, was initially considered; if found to be non-significant ( $P>0.05)$, these were dropped from the model.

\section{Model building}

Stage 0: Treatment effect. At this stage, change in HbA1c level was modelled as a function of the treatment group, while

\section{Table 1. Mean summary statistics by sex}

\begin{tabular}{|c|c|c|c|}
\hline Variable & Female & Male & All \\
\hline$n$ & 1643 & 1773 & 3416 \\
\hline Age at baseline, years (SD) & $61(13)$ & $56(12)$ & $58(13)$ \\
\hline BMI at baseline (SD) & $31.5(11.3)$ & $30.7(9.8)$ & $31.0(11)$ \\
\hline Duration in study, years (SD) & $10(4)$ & $10(4)$ & $10(4)$ \\
\hline HbA1c level at baseline (SD) & $7.1(1.9)$ & $7.2(2.0)$ & $7.1(2.0)$ \\
\hline $\mathrm{HbA} 1 \mathrm{c}>7, \%$ & 38 & 39 & 38 \\
\hline \multicolumn{4}{|l|}{ Comorbidity, $n[\%]$} \\
\hline Respiratory & $212(13)$ & 229 (13) & 441 (13) \\
\hline Anaemia & $113(7)$ & $65(4)$ & $178(5)$ \\
\hline Depression & $240(15)$ & 166 (9) & 406 (12) \\
\hline Malignancy & $65(4)$ & $119(7)$ & $184(5)$ \\
\hline Joint disorders & 1362 (83) & $1365(77)$ & $2727(80)$ \\
\hline Any comorbidity & $1415(86)$ & $1436(81)$ & $2851(84)$ \\
\hline \multicolumn{4}{|l|}{ Comedication, $n(\%)$} \\
\hline Corticosteroids & 578 (35) & $542(31)$ & 1120 (33) \\
\hline Antidepressant & 557 (34) & $398(22)$ & 955 (28) \\
\hline NSAID & $1215(74)$ & $1263(71)$ & 2478 (73) \\
\hline Any comedication & $882(54)$ & $882(50)$ & $1764(52)$ \\
\hline \multicolumn{4}{|l|}{ Treatment, $n(\%)$} \\
\hline OAD & $382(23)$ & $455(26)$ & 837 (25) \\
\hline OAD and insulin & 849 (52) & $900(51)$ & $1749(51)$ \\
\hline Insulin & 55 (3) & $52(3)$ & 107 (3) \\
\hline Diet & $357(22)$ & $366(21)$ & $723(21)$ \\
\hline
\end{tabular}

$B M I=$ body mass index $. H B A 1 C=$ glycosylated haemoglobin. $N S A I D=$ non-steroidal anti-inflammatory drug . $O A D=$ oral antidiabetic drug. $S D=$ standard deviation . adjusting for potential confounders such as age and sex, together with their meaningful interactions.

Stage 1: Comorbidity effect. In this stage, the model in Stage 0 was extended with the presence or absence of each comorbid disease. The effect of each comorbidity on the change in $\mathrm{HbA} 1 \mathrm{c}$ level was investigated and adjusted for treatment group, age, and sex; testing for the presence of an interaction between the treatment group and comorbid disorder was also undertaken. Presence of a second or third disease, additional to the first one was then investigated, adjusting for the other variables.

Stage 2: Comedication effect. Similar analyses as in Stage 1 were performed but the effect of drug treatment instead of comorbidity was examined.

Stage 3: Effect of comorbidity and comedication. In this stage, the effects of combinations of diseases and drugtreatment classes that were significant in Stages 1 and 2 were examined.

\section{RESULTS}

\section{Exploratory data analysis}

Data from 3416 patients were analysed. There were no major differences between males and females with respect to given covariates at baseline (Table 1). On average, females were slightly older than males, and their mean $\mathrm{HbA} 1 \mathrm{c}$ level at baseline was slightly lower. However, the percentage of patients with $\mathrm{HbA} 1 \mathrm{c}>7.0$ was, more or less, equal in both groups. Duration in the study ranged from 0 to 14 years, with the average being 9.9 years. Of the patients, $84 \%$ had at least one of the five comorbidities and $52 \%$ used at least one of the three medications. Two patients (one male, one female) had all five comorbidities. Most patients (80\%) had joint disorders and the average BMI was 31.0. Just over half of the patients received combined treatment loral antidiabetic drugs and insulin); a very small proportion $(3 \%)$ were treated with insulin only.

\section{Crude data analysis}

HbA1c level improved during the study period in 2046 (60\%) patients. The probability of a worsening in $\mathrm{HbA1c}$ level, given presence compared with absence of comorbidity or comedication was higher in all cases but anaemia (Table 2). Similar observations from $2 \times 2$ cross-tabulation of combined comorbidity and comedication were noted. 


\begin{tabular}{|c|c|c|c|}
\hline \multirow[b]{2}{*}{ Variable } & & \multicolumn{2}{|c|}{ Change in $\mathrm{HbA} 1 \mathrm{c}, \%^{\mathrm{a}}$} \\
\hline & & $\leq 0$ & $>0$ \\
\hline \multirow[t]{2}{*}{ Respiratory disorders } & Absent & 60 & 40 \\
\hline & Present & 56 & 44 \\
\hline \multirow[t]{2}{*}{ Anaemia } & Absent & 60 & 40 \\
\hline & Present & 62 & 38 \\
\hline \multirow[t]{2}{*}{ Depression } & Absent & 60 & 40 \\
\hline & Present & 57 & 43 \\
\hline \multirow[t]{2}{*}{ Joints disorders } & Absent & 68 & 33 \\
\hline & Present & 58 & 42 \\
\hline \multirow[t]{2}{*}{ Malignancy } & Absent & 60 & 40 \\
\hline & Present & 57 & 44 \\
\hline \multirow[t]{2}{*}{ Corticosteroids } & Absent & 62 & 38 \\
\hline & Present & 56 & 45 \\
\hline \multirow[t]{2}{*}{ Antidepressants } & Absent & 60 & 40 \\
\hline & Present & 58 & 44 \\
\hline \multirow[t]{2}{*}{ NSAIDs } & Absent & 66 & 34 \\
\hline & Present & 58 & 42 \\
\hline \multicolumn{2}{|l|}{ At least any of these present } & 60 & 40 \\
\hline \multicolumn{4}{|c|}{$\begin{array}{l}\text { aPercentage of the subjects with better (change in } \mathrm{HbA1} c \leq 0 \text { ) or worse (change in } \mathrm{HbA1c}>0 \text { ) outcome levels } \\
\text { at the end of the study period. Some figures total more than } 100 \% \text { due to rounding. HbA1c = glycosylated } \\
\text { haemoglobin. NSAID = non-steroidal anti-inflammatory drug. }\end{array}$} \\
\hline
\end{tabular}

Multivariate analysis

In each stage of model building, age and sex were covariates of interest; as such,

\section{Table 3. Effect of treatment on $\mathrm{HbA} 1 \mathrm{c}$ evolution in relation to presence of chronic comorbidity and medication, obtained using multiple logistic regression analysis. Results are adjusted for age and sex}

\begin{tabular}{|c|c|c|c|c|}
\hline & $\begin{array}{l}\text { Diet only, } \\
\text { OR }(95 \% \mathrm{CI})\end{array}$ & $\begin{array}{l}\text { Oral drugs, } \\
\text { OR }(95 \% \mathrm{CI})\end{array}$ & $\begin{array}{l}\text { Combination, } \\
\text { OR }(95 \% \mathrm{CI})\end{array}$ & $\begin{array}{l}\text { Insulin only, } \\
\text { OR (95\% CI) }\end{array}$ \\
\hline No comorbidity, no medication & 1.00 & $\begin{array}{c}1.39 \\
(1.16 \text { to } 1.66)\end{array}$ & $\begin{array}{c}1.36 \\
(1.07 \text { to } 1.74)\end{array}$ & $\begin{array}{c}0.96 \\
(0.67 \text { to } 1.37)\end{array}$ \\
\hline \multicolumn{5}{|l|}{ Comorbidity } \\
\hline Joint disorders & $\begin{array}{c}1.04 \\
(0.71 \text { to } 1.53)\end{array}$ & $\begin{array}{c}1.57 \\
(1.00 \text { to } 2.47)\end{array}$ & $\begin{array}{c}1.32 \\
\text { (0.73 to } 2.36)\end{array}$ & $\begin{array}{c}2.51 \\
\text { (1.05 to } 6.02 \text { ) }\end{array}$ \\
\hline Respiratory disorders & $\begin{array}{c}0.81 \\
\text { (0.51 to } 1.27 \text { ) }\end{array}$ & $\begin{array}{c}1.55 \\
\text { (0.92 to 2.62) }\end{array}$ & $\begin{array}{c}2.00 \\
(0.97 \text { to } 4.11)\end{array}$ & $\begin{array}{c}3.06 \\
11.05 \text { to } 8.91\end{array}$ \\
\hline Respiratory + joint disorders & & $\begin{array}{c}1.34 \\
\text { (1.11 to } 1.69 \text { ) }\end{array}$ & & \\
\hline \multicolumn{5}{|l|}{ Medication } \\
\hline Corticosteroids & $\begin{array}{c}1.31 \\
\text { (1.13 to } 1.52 \text { ) }\end{array}$ & $\begin{array}{c}1.39 \\
\text { (1.16 to } 1.66)\end{array}$ & $\begin{array}{c}1.35 \\
(1.06 \text { to } 1.72)\end{array}$ & $\begin{array}{c}0.97 \\
\text { (0.68 to 1.38) }\end{array}$ \\
\hline NSAID & $\begin{array}{c}1.34 \\
\text { (1.14 to } 1.58 \text { ) }\end{array}$ & $\begin{array}{c}1.36 \\
(1.13 \text { to } 1.62)\end{array}$ & $\begin{array}{c}1.34 \\
(1.05 \text { to } 1.70)\end{array}$ & $\begin{array}{c}0.97 \\
\text { (0.68 to } 1.39 \text { ) }\end{array}$ \\
\hline Corticosteroids + NSAID & $\begin{array}{c}1.41 \\
(1.21 \text { to } 1.64)\end{array}$ & $\begin{array}{c}1.38 \\
\text { (1.16 to } 1.65 \text { ) }\end{array}$ & $\begin{array}{c}1.36 \\
(1.07 \text { to } 1.73)\end{array}$ & $\begin{array}{c}0.99 \\
\text { (0.69 to } 1.41)\end{array}$ \\
\hline
\end{tabular}

\section{Comorbidity + medication}

Respiratory + joint disorders + NSAID

0.95

1.53

1.55

4.32

(0.57 to 1.57$) \quad(0.85$ to 2.75$) \quad$ (0.69 to 3.50$) \quad(1.23$ to 15.13$)$

BMI did not significantly add to the modelling. Reference group for all OR: patients with no medication, no comorbidity, diet only. No interaction between treatment effect and treatment group. All results given in bold are statistically significant. $B M I=$ body mass index. NSAID = non-steroidal anti-inflammatory drug. OR = odds ratio they were kept in all subsequent models, even if they were not always found to be significant.

\section{Stage 0: Treatment effect}

The odds of increased HbA1c levels at study end (worse outcome) were around 40\% higher for patients on oral antidiabetic drugs or a combination of oral antidiabetic drugs and insulin than for patients treating their diabetes with diet alone (Table 3).

\section{Stage 1: Comorbidity effect}

A significant increase in $\mathrm{HbA1c}$ level was associated with the presence of joint disorders in the groups of patients treated with oral antidiabetic drugs lodds ratio [OR] 1.57) and insulin only (OR 2.51) while, in patients treated with insulin only, respiratory disorders were found to have a significant effect (OR 3.06) (Table 3). Effects of anaemia, depression, and malignancy on treatment efficacy were not found to be significant.

When investigating the effect of an additional comorbidity, only the effect of both respiratory and joint disorders was found to be significant (OR 1.34). There was no interaction with treatment group.

\section{Stage 2: Comedication effect}

The effect of corticosteroids and NSAIDs on outcome was significant, separately as well as in combination (Table 3). No significant interaction between treatment group and comedication was noted: corticosteroids/ oral antidiabetic drugs ( $P$-value 0.12$)$; corticosteroids/oral antidiabetic drugs and insulin ( $P$-value 0.27); corticosteroids/insulin ( $P$-value 0.99); NSAIDs/oral antidiabetic drugs ( $P$-value 0.96 );

NSAIDs/oral antidiabetic drugs and insulin ( $P$-value 0.86); and NSAID/insulin ( $P$-value 0.52). There was a $30-40 \%$ higher chance that the HbA1c levels were increased at the end of the study period if comedication was present.

\section{Stage 3: comorbidity and comedication effect}

The odds of elevated $\mathrm{HbA} 1 \mathrm{c}$ levels at the end of the study for patients with joint and respiratory disorders, who were taking NSAIDs and insulin, were four times that of patients treating their diabetes with diet only, who did not belong to this class of comorbidity and comedication. Other combinations were not significant.

\section{DISCUSSION}

\section{Summary}

In this study, the coexistence of joint and respiratory disorders, with or without the 
prescription of corticosteroids, NSAIDs, or both, was associated with poorer glucose control compared to no comorbidity. This is meaningful in relation to joint problems because these reduce physical activity that is considered a cornerstone of optimal diabetes control. ${ }^{1,23}$ Additionally, joint problems tend to be unstable over time, resulting in irregular increases and decreases of the type and dosage of drugs taken, which make stable glycaemia control more difficult to achieve.

Of interest is the large proportion ( $>80 \%$ ) of patients who had joint disorders. These findings are in line with those of other recent studies about the association between diabetes and various musculoskeletal manifestations. ${ }^{24}$ In addition, the findings that respiratory disorders are associated with poor glycaemic control are in agreement with several findings in literature. ${ }^{25-27}$ There was no effect of anaemia, depression, or malignancy.

\section{Strengths and limitations}

The strengths of this study lay in its large sample size and the laboratory-measured response with complete data. Additionally, a retrospective cohort design was used; this is a very strong design in epidemiology, in which robust data are collected and stored over time. A large amount of data that had been collected and stored in the past was analysed using a cohort design; by doing this, information collected tempore non suspecto could be used, avoiding the main risks of bias, especially selection and recall bias, that often occur in retrospective studies.

Weaknesses were also noted. No details were available about each comorbidity and comedication, which could include disorders or drugs with different characteristics. The categorisation employed in this study was a compromise between specificity and practicality. Only date of diagnosis or first prescription was recorded. Severity of the comorbidities are potential confounders, ${ }^{28}$ although use of corticosteroids, for example, may be a proxy for disease severity in respiratory and joint disorders.

The effect of five comorbidities and three groups of medication, which to the authors' knowledge is more than has ever been done before, were examined. However, more chronic diseases and more groups of medication that may also influence glycaemic control exist; if related to the predictors used, these might confound these results. Smoking status and other lifestyle behaviours that influence glycaemic control were insufficiently captured and, therefore, not used in the analysis. In addition, although a generic measure of the outcome status of the patients would have been helpful, such information is not available in the Intego database.

The derivation of the response used in this study is susceptible to random variation in the HbA1c levels at the end of the study. To check for the possible effect of this phenomenon, these data were initially recalculated, taking into consideration only an increase in $\mathrm{HbA} 1 \mathrm{c}$ level larger than the standard deviation of the overall mean as a worse outcome. In addition, only a difference between the initial and the last observation of $>1$ unit of $\mathrm{HbAlc}$ was considered as evidence of elevated $\mathrm{HbA1c}$. As the results from modelling did not differ a great deal, the initial response was maintained. In an alternative approach, a repeated-measures analysis on each subject, rather than the change in $\mathrm{HbAlc}$ level from the initial to the last available level, was performed. Two techniques taken into consideration were the linear mixed models for continuous $\mathrm{HbA1c}$ level and the generalised estimating equations for the dichotomised $\mathrm{HbA} 1 \mathrm{c}$ level, based on the $7 \%$ stable cut-off point. Both analyses gave largely similar results to those reported in this article.

A further point to note is that some of the patients had been diagnosed with diabetes before the start of the registration period. This could bias the results as incident and prevalent cases were considered together so the second year of follow-up was considered the initial year into the study for each patient and the response was derived in a similar fashion. In this way, only patients who had had diabetes for at least 1 year were considered. There were no significant changes in results.

Differences between treatment groups in age at baseline and sex subgroups were significant, as was the absence of any comorbidity or comedication. However, this has no real influence on the study conclusions as all analyses were adjusted for treatment group, age, and sex.

This study did not find any association between depressive disorders and worsening $\mathrm{HbAlc}$ levels: a finding that contradicts those of several other studies that did find such an association. ${ }^{29,30 ~ I n ~}$ addition, a recent trial showed that, in patients who were simultaneously treated for both type 2 diabetes and depression, medication compliance, blood-sugar, and depression levels significantly improved, compared with patients receiving usual care. ${ }^{31}$ A possible explanation is that coded depressive disorders in primary care may 
differ from the diagnosis of major depression in patients selected for prospective cohort studies.

\section{Comparison with existing literature}

No effect was found relating to malignancy or anaemia; this could be a result of complex mechanisms either increasing (for example, some drug treatment) or decreasing (for example, weight loss) $\mathrm{HbA1}$ levels in interactions with routine diabetes care.

Few studies have reported on the effect of comedication. Faul et $a^{\beta^{2}}$ did not find a significant impact of corticosteroid use on changes in $\mathrm{HbA} 1 \mathrm{c}$ levels, despite suggesting careful monitoring of blood glucose levels for patients initiating use of corticosteroids. It seems sensible that, although starting corticosteroids or a change in dosage can lead to short periods of increased glycaemia chronic corticosteroid use is easily controlled by adapting the treatment prescription. These results also pointed to treatment with NSAIDs being associated with an increased risk of elevated $\mathrm{HbA} 1 \mathrm{c}$ levels. It is interesting to note that the comorbidities and NSAID treatments seemed to have an independent effect without meaningful interaction; in fact, the effect of each of them separately seemed to have a magnitude that was, more or less, similar; this was not cumulative when the treatments were combined. This may be important as the population under consideration is ageing and, hence, most patients with diabetes are likely to be prescribed more than one medication for a chronic condition.

\section{Implications for research and practice}

This study once more confirms the need for comprehensive guidelines to effectively care for patients with multiple diseases; these guidelines should be as generic as possible but could include adapted metabolic targets discussed on the basis of patientspecific treatment goals. The findings of this study could add to the body of evidence underpinning such new guidelines.

This study was performed in a population of patients with type 2 diabetes. However, in the future, a generic set-up must be developed to study all combinations of chronic diseases and chronic drug therapy. Ongoing databases of routinely collected information - such as the General Practice Research Database (UK), Intego (Belgium), RegistratieNet Huisartsgeneeskunde (The Netherlands) - seem to be a good framework for such studies. However, for most chronic disorders it may be difficult to identify good-quality outcome indicators that are routinely recorded in these databases.

\section{Funding}

The Intego registry is being funded by the Minister of Health and Welfare of the Flemish government and the Belgian National Institute for Health and Disability Insurance (Achil project). No funding was received for this study.

\section{Ethical approval}

The Intego procedures have been approved by the ethical review board of the Medical School of KU Leuven (reference number: ML1723).

\section{Provenance}

Freely submitted; externally peer reviewed.

\section{Competing interests}

The authors have declared no competing interests.

\section{Acknowledgements}

This work would not have been possible without the collaboration of all GPs of the Intego network.

\section{Discuss this article}

Contribute and read comments about this article on the Discussion Forum: http://www.rcgp.org.uk/bjgp-discuss 


\section{REFERENCES}

1. Wild S, Roglic G, Green A, et al. Global prevalence of diabetes: estimates for the year 2000 and projections for 2030. Diabetes Care 2004; 27(5): 1047-1053.

2. International Diabetes Federation. IDF diabetes atlas. 5th edn. Belgium: IDF, 2009. http://www.diabetesatlas.org/content/europe laccessed 27 Feb 2013).

3. American Diabetes Association. Standards of medical care in diabetes - 2012. Diabetes Care 2012; 35 Suppl 1: S11-S63.

4. American Diabetes Association; European Association for the Study of Diabetes: International Federation of Clinical Chemistry and Laboratory Medicine; International Diabetes Federation. Consensus statement on the worldwide standardisation of the HbA1c measurement. Diabetologia 2007; 50(10): 20422043.

5. Feinglos MN, Bethel MA. Type 2 diabetes mellitus. An evidenced based approach to practical management. New York, NY: Humana Press, 2008.

6. Goderis G, Borgermans L, Heyrman J, et al. Type 2 diabetes in primary care in Belgium: need for structured shared care. Exp Clin Endocrinol Diabetes 2009; 117(8): 367-372

7. Resnick HE, Foster GL, Bardsley J, Ratner RE. Achievement of American Diabetes Association clinical practice recommendations among U.S. adults with diabetes, 1999-2002: the National Health and Nutrition Examination Survey. Diabetes Care 2006; 29(3): 531-537.

8. Wan Q, Harris MF, Jayasinghe UW, et al. Quality of diabetes care and coronary heart disease absolute risk in patients with type 2 diabetes mellitus in Australian general practice. Qual Saf Health Care 2006; 15(2): 131-135.

9. Yurgin N, Secnik K, Lage MJ. Antidiabetic prescriptions and glycemic control in German patients with type 2 diabetes mellitus: a retrospective database study. Clin Ther 2007; 29(2): 316-325

10. Hoffman C, Rice D, Sung HY. Persons with chronic conditions. Their prevalence and costs. JAMA 1996; 276(18): 1473-1479.

11. van Weel C, Schellevis FG. Comorbidity and guidelines: conflicting interests. Lancet 2006; 367(9510): 550-551.

12. Guthrie $B$, Payne $K$, Alderson $P$, et al. Adapting clinical guidelines to take account of multimorbidity. BMJ 2012; 345: e6341.

13. Kernick D. A theoretical framework for multimorbidity: from complicated to chaotic. Br J Gen Pract 2012; DOI: 10.3399/bjgp12X654740.

14. Inzucchi SE, Bergenstal RM, Buse JB, et al. Management of hyperglycaemia in type 2 diabetes: a patient-centered approach. Position statement of the American Diabetes Association (ADA) and the European Association for the Study of Diabetes (EASD). Diabetologia 2012; 55: 1577-1996.

15. Van den Akker M, Buntinx F, Knottnerus JA. Comorbidity or multimorbidity: what's in a name? A review of literature. Eur J Gen Pract 1996; 2(2): 67-70.
16. Piette JD, Kerr EA. The impact of comorbid chronic conditions on diabetes care. Diabetes Care 2006; 29(3): 725-731.

17. Hudon C, Fortin M, Dubois MF, Almirall J. Comorbidity and glycemia control among patients with type 2 diabetes in primary care. Diabetes Metab Syndr Obes 2008; 1: 33-37.

18. Zhang Q, Safford M, Ottenweller J, et al. Performance status of health care facilities changes with risk adjustment of HbA1c. Diabetes Care 2000; 23(7): 19-27.

19. Weiner M, Long J. Cross-sectional versus longitudinal performance assessments in the management of diabetes. Med Care 2004; 42(2 Suppl): 1134-1139

20. Suh DC, Kim CM, Choi IS, et al. Comorbid conditions and glycemic control in elderly patients with type 2 diabetes mellitus, 1988 to1994 to 1999 to 2004. J Am Geriatr Soc 2008; 56(3): 484-492.

21. El-Kebbi IM, Ziemer DC, Cook CB, et al. Comorbidity and glycemic control in patients with type 2 diabetes. Arch Int Med 2001; 161(10): 1295-300.

22. Department of General Practice, KU Leuven. Intego-project. [Online]. http:// muw.intego.be laccessed 27 Feb 2013).

23. Smith LL, Burnet SP, McNeil JD. Musculoskeletal manifestations of diabetes mellitus. Br J Sports Med 2003; 37(1): 30-35.

24. Lebiedz-Odrobina D, Kay J. Rheumatic manifestations of diabetes mellitus. Rheum Dis Clin North Am 2010; 36(4): 681-699.

25. Walter RE, Beiser A, Givelber RJ, et al. Association between glycemic state and lung function: the Framingham Heart Study. Am J Respir Crit Care Med 2003; 167(6): 911-916.

26. BloomgardenZT. American Diabetes Association Annual Meeting, 1999: more on cardiovascular disease. Diabetes Care 2000; 23(6): 845-852.

27. Moller DE. Potential role of TNF-alpha in the pathogenesis of insulin resistance and type 2 diabetes. Trends Endocrinol Metab 2000; 11(6): 212-217.

28. Menzin J, Korn JR, Cohen J, et al. Relationship between glycemic control and diabetes-related hospital costs in patients with type 1 or type 2 diabetes mellitus. J Manag Care Pharm 2010; 16(4): 264-275.

29. Lustman PJ, Anderson RJ, Freedland KE, et al. Depression and poor glycemic control: a meta-analytic review of the literature. Diabetes Care 2000; 23(7): 934-942.

30. Papelbaum M, Moreira RO, Coutinho W, et al. Depression, glycemic control, and type 2 diabetes. Diabetol Metab Syndr 2011; 3(1): 26.

31. Lin EHB, Katon W, Rutter $C$, et al. Effects of enhanced depression treatment on diabetes self-care. Ann Fam Med 2006; 4(1): 46-53.

32. Faul JL, Wilson SR, Chu JW, et al. The effect of an inhaled corticosteroid on glucose control in type 2 diabetes. Clin Med Res 2009; 7(1-2): 14-20. 